\title{
Feature tracking strain is similar to harmonic phase cardiac magnetic resonance in Fontan patients: a validation study
}

\author{
Shafkat Anwar ${ }^{1 *}$, Elisha J Fogel ${ }^{1}$, Ravi Doddasomayajula', Alexander Davidson', Marc S Keller², Matthew A Harris ${ }^{1}$, \\ Kevin K Whitehead ${ }^{1}$, Mark A Fogel ${ }^{1}$
}

From 17th Annual SCMR Scientific Sessions

New Orleans, LA, USA. 16-19 January 2014

\section{Background}

Feature tracking strain (FTS) is a new technique to evaluate myocardial deformation from routinely acquired cardiac magnetic resonance (CMR) cine images, however, it has not been validated in single ventricle patients. The purpose of this study is to validate FTS against myocardial tagged harmonic phase (HARP) images, considered the reference standard in non-invasive deformation analysis.

\section{Methods}

We retrospectively analyzed CMRs of 15 consecutive single ventricle Fontan patients (Table 1) with myocardial tagging and balanced steady state free precession (SSFP) cine images in the same study. Off-line analysis was performed on basal, mid and apical short axis levels using Diagnasoft Virtue (v4.5.1) and TomTec 2D Cardiac Performance Analysis (v 1.0) for HARP and FTS, respectively. Lagrangian endocardial strain was compared between techniques.

\section{Results}

There was good correlation in global circumferential strain (GCS) between HARP and FTS, Pearson $r=0.67$, $\mathrm{p}=0.006$. Average GCS was -19 (95\% CI -4.3 to -33.8$)$ from HARP and -16.7 (95\% CI -6.4 to -26.9$)$ from FTS. FTS yielded lower values (bias -2.3) than HARP (Figure 1), equivalent to a bias of $12.3 \%$ (average bias of FTS/average HARP $\times 100)$. This difference was not significant via Student's T-test $(t=3, D F 13, p=0.1)$. Analysis of variance (ANOVA) showed considerable overlap in

'Pediatrics, Cardiology, The Children's Hospital of Philadelphia, Philadelphia, Pennsylvania, USA

Full list of author information is available at the end of the article
Table 1 Demographics.

\begin{tabular}{ll}
\hline Subjects, $\mathrm{n}$ & 15 \\
\hline Age in years, media (range) & $18(5-38)$ \\
\hline Single ventricle morphology (LV:RV) & $7: 8$ \\
\hline Double outlet right ventricle, $\mathrm{n}$ & 5 \\
\hline Hypolastic left heart syndrome, $\mathrm{n}$ & 4 \\
\hline Tricuspid atresia & 3 \\
\hline Pulmonary atresia, intact ventricular septum, $\mathrm{n}$ & 1 \\
\hline Unbalanced AV canal, $\mathrm{n}$ & 1 unbalanced to left \\
& 1 unbalanced to right \\
\hline
\end{tabular}

measurements, $\mathrm{F}=2.64, \mathrm{p}=0.04$. Intraclass correlation was 0.58 , indicating moderate agreement.

\section{Conclusions}

Feature tracking analysis has moderate agreement with grid-tagged HARP measurements of circumferential strain in Fontan patients, with a trend towards lower strain values via FTS. Further validation of FTS in a large sample is warranted.

\section{Funding}

Dr Kevin K. Whitehead: NIH K23 Grant HL089647 from the National Heart, Lung and Blood Institute. Dr. Mark Fogel: NIH R01HL098252-01, "Understanding mechanisms of Fontan failure and key predictors for patient outcome."

\section{Authors' details \\ 'Pediatrics, Cardiology, The Children's Hospital of Philadelphia, Philadelphia, Pennsylvania, USA. ²Pediatrics, Radiology, The Children's Hospital of} Philadelphia, Philadelphia, Pennsylvania, USA. 


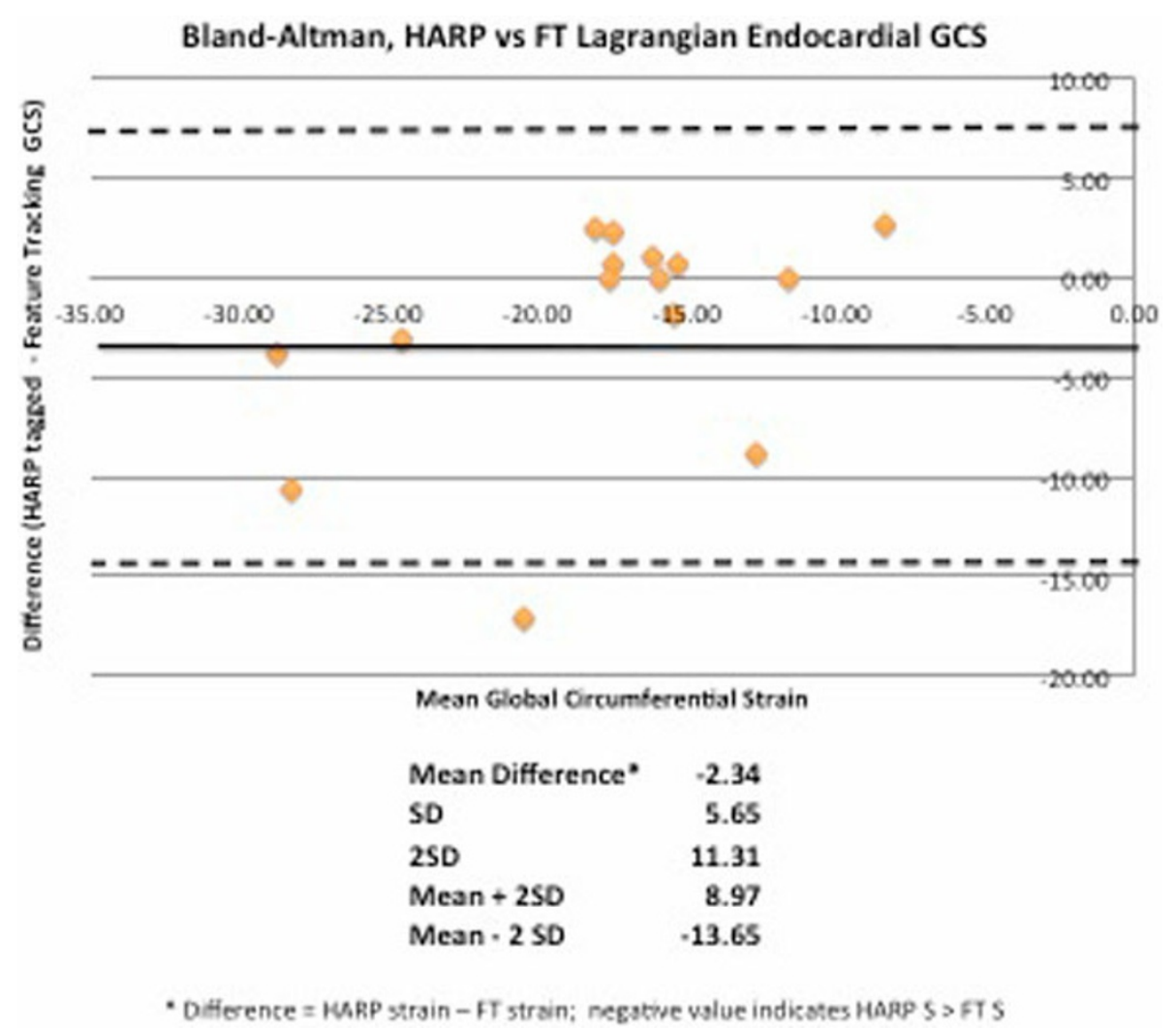

Figure 1 Bland-Altman HARP vs Feature Tracking Strain.

Published: 16 January 2014

doi:10.1186/1532-429X-16-S1-P106

Cite this article as: Anwar et al.: Feature tracking strain is similar to

harmonic phase cardiac magnetic resonance in Fontan patients: a

validation study. Journal of Cardiovascular Magnetic Resonance 201416

(Suppl 1):P106.

Submit your next manuscript to BioMed Central and take full advantage of:

- Convenient online submission

- Thorough peer review

- No space constraints or color figure charges

- Immediate publication on acceptance

- Inclusion in PubMed, CAS, Scopus and Google Scholar

- Research which is freely available for redistribution

Submit your manuscript at www.biomedcentral.com/submit 